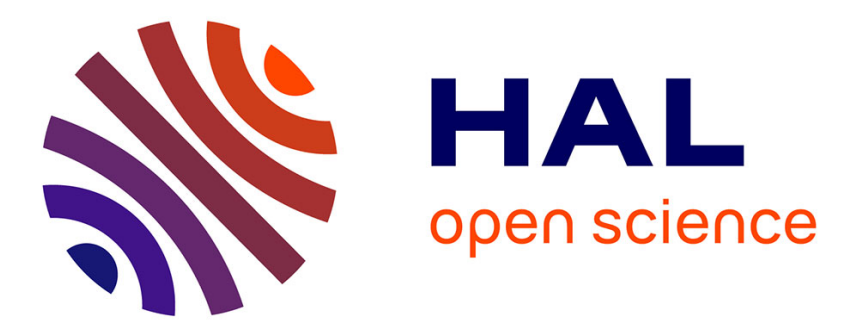

\title{
Life-History Traits Evolved Jointly with Climatic Niche and Disturbance Regime in the Genus Leucadendron (Proteaceae)
}

Jeanne Tonnabel, Frank Schurr, Florian Boucher, Wilfried Thuiller, Julien Renaud, Emmanuel J.P. Douzery, Ophélie Ronce

\section{To cite this version:}

Jeanne Tonnabel, Frank Schurr, Florian Boucher, Wilfried Thuiller, Julien Renaud, et al.. Life-History Traits Evolved Jointly with Climatic Niche and Disturbance Regime in the Genus Leucadendron (Proteaceae). American Naturalist, 2018, 191 (2), pp.220-234. 10.1086/695283 . hal-02382563

\section{HAL Id: hal-02382563 https://hal.science/hal-02382563}

Submitted on 27 Nov 2019

HAL is a multi-disciplinary open access archive for the deposit and dissemination of scientific research documents, whether they are published or not. The documents may come from teaching and research institutions in France or abroad, or from public or private research centers.
L'archive ouverte pluridisciplinaire HAL, est destinée au dépôt et à la diffusion de documents scientifiques de niveau recherche, publiés ou non, émanant des établissements d'enseignement et de recherche français ou étrangers, des laboratoires publics ou privés. 


\title{
Life-History Traits Evolved Jointly with Climatic Niche and Disturbance Regime in the Genus Leucadendron (Proteaceae)
}

\author{
Jeanne Tonnabel, ${ }^{1,2, *}$ Frank M. Schurr, ${ }^{1,3}$ Florian Boucher, ${ }^{4,5}$ Wilfried Thuiller, ${ }^{4}$ Julien Renaud, ${ }^{4}$ \\ Emmanuel J. P. Douzery, ${ }^{1}$ and Ophélie Ronce ${ }^{1}$
}

1. Institut des Sciences de l'Évolution (Unité Mixte de Recherche 5554), Université de Montpellier, Centre National de la Recherche Scientifique (CNRS), Institut de Recherche pour le Développement (IRD), École Pratique des Hautes Études (EPHE), Place Eugène Bataillon, 34095 Montpellier cedex 05, France; 2. Department of Ecology and Evolution, Le Biophore, Quartier UNIL-Sorge, University of Lausanne, CH-1015 Lausanne, Switzerland; 3. Institute of Landscape and Plant Ecology, University of Hohenheim, 70593 Stuttgart, Germany; 4. Université Grenoble Alpes, Laboratoire d'Écologie Alpine (LECA), F-38000 Grenoble, France; and CNRS, LECA, F-38000 Grenoble, France; 5. Department of Botany and Zoology, University of Stellenbosch, Private Bag X1, Matieland 7602, South Africa

Submitted August 31, 2016; Accepted August 14, 2017; Electronically published December 5, 2017

Online enhancements: appendix.

\begin{abstract}
AвSTRACт: Organisms have evolved a diversity of life-history strategies to cope with variation in their environment. Persistence as adults and/or seeds across recruitment events allows species to dampen the effects of environmental fluctuations. The evolution of life cycles with overlapping generations should thus permit the colonization of environments with uncertain recruitment. We tested this hypothesis in Leucadendron (Proteaceae), a genus with high functional diversity native to fire-prone habitats in the South African fynbos. We analyzed the joint evolution of life-history traits (adult survival and seed-bank strategies) and ecological niches (climate and fire regime), using comparative methods and accounting for various sources of uncertainty. In the fynbos, species with canopy seed banks that are unable to survive fire as adults display nonoverlapping generations. In contrast, resprouters with an underground seed bank may be less threatened by extreme climatic events and fire intervals, given their iteroparity and long-lasting seed bank. Life cycles with nonoverlapping generations indeed jointly evolved with niches with less exposure to frost but not with those with less exposure to drought. Canopy seed banks jointly evolved with niches with more predictable fire return, compared to underground seed banks. The evolution of extraordinary functional diversity among fynbos plants thus reflects, at least in part, the diversity of both climates and fire regimes in this region.
\end{abstract}

Keywords: functional traits, niche evolution, comparative analyses, bet hedging, seed bank, fire.

\section{Introduction}

The evolution of life histories is thought to be largely shaped by environmental variability and its predictability (see

* Corresponding author; e-mail: jeanne.tonnabel@unil.ch. ORCIDs: Douzery, http://orcid.org/0000-0001-5286-647X.

Am. Nat. 2018. Vol. 191, pp. 000-000. (C) 2017 by The University of Chicago. 0003-0147/2018/19102-57222\$15.00. All rights reserved. DOI: $10.1086 / 695283$
Schaffer 1974, Iwasa and Kubo 1997, Tuljapurkar et al. 2009, and Fischer et al. 2011 for some theoretical predictions). Organisms have evolved various traits to cope with temporarily harsh conditions, to exploit temporarily favorable conditions, and to cope with uncertainty in when these occur. Bet-hedging strategies, for example, the evolution of seed banks in plants (Childs et al. 2010), reflect such adaptations to variable environments. Bet-hedging strategies trade mean performance against reduced temporal variance or reduced correlations in reproductive success among individuals of the same lineage (Starrfelt and Kokko 2012; Tufto 2015). Iteroparous organisms, which reproduce repeatedly during their lifetime, spread their reproductive effort across several recruitment events, while semelparous ones, reproducing once in their lifetime, rely on a single recruitment event to leave successful progeny. In the presence of variable juvenile survival, iteroparity should be favored over semelparity as a bet-hedging strategy (see Schaffer 1974 and Orzack and Tuljapurkar 1989 for theoretical predictions and Morris et al. 2008 for empirical data). Iteroparity is also predicted to evolve in environments where the mean recruitment rate is low relative to mean adult survival (Charnov and Schaffer 1973). Seed banks and adult survival strategies should, furthermore, coevolve along environmental gradients (Koons et al. 2008; Scott and Otto 2014). Despite an abundant theoretical literature on how life histories evolve in variable environments, there are still few microevolutionary empirical tests of such predictions (e.g., Gremer and Venable 2014; Rajon et al. 2014; Cayuela et al. 2016) and even fewer tests at the macroevolutionary scale (Simons 2011). Here, we take advantage of an exceptional data set for the genus Leucadendron from 
the South African fynbos to test the theory in a quantitative comparative framework. In particular, we test predictions of life-history theory by studying the joint evolution of both persistence and regeneration traits with both climate and disturbance regime in a macroevolutionary context.

Extreme climatic events and disturbances, such as fires, strongly affect survival rates and fecundities in natural populations. Such events also vary in predictability. We therefore expect species' life-history traits to evolve in response to prevailing disturbance regimes and climatic conditions. On the other hand, life-history traits are increasingly recognized as playing an important role in how climatic niches evolve. The ecological niche of a species is defined by the set of environmental conditions in which a species can grow and persist (Hutchinson 1957). Changes in a species niche are often characterized as a change in its niche position along a specific environmental gradient (e.g., mean annual temperature within the species' range). Comparative analyses of niche macroevolution in plants have revealed that the evolution of some key morphological traits can allow the colonization of stressful environments within arid or cold climates (Boucher et al. 2012; Evans et al. 2014; Zanne et al. 2014). The evolution of specific life histories indeed seems to facilitate niche evolution toward extreme climates, such as perenniality at high altitudes (e.g., Boucher et al. 2012; Kostikova et al. 2013; Ogburn and Edwards 2015), viviparity in cold environments (Mesquita et al. 2016), and resprouting in the presence of drought after fire (Litsios et al. 2014). Macroevolutionary tests of the joint evolution of lifehistory traits and niche position along gradients of disturbance, however, are scarce, reflecting in part the rarity of long-term data on disturbance events for many species.

In Mediterranean-type fire-prone ecosystems, plants display life-history traits (called "fire-related traits") that enable populations to regenerate after fire through either seed storage in fireproof locations or the ability of some adults to survive the fire (reviewed in Keeley et al. 2012). Nonsprouters are killed by fire, whereas resprouters regenerate after fires from protected buds (Bond and Midgley 2001). Seed recruitment in fire-prone environments mostly occurs immediately after a fire (Cowling and Lamont 1987). The successful reproduction of nonsprouters thus relies on a single recruitment period, similar to that of species with semelparous life histories (Bond and van Wilgen 1996; see the recent review by Pausas and Keeley [2014]). In fire-prone environments, plants can store their seeds either in persistent underground seed banks or in "serotinous" seed banks, defined as stored within the canopy (Lamont et al. 1991). Germination in species with underground seed banks is usually triggered by fires (Brown 1993), but some proportion may fail to germinate after a first fire, remaining dormant until the next (Auld and Denham 2006; van Wilgen 2013; see, however, Holmes 2002). In contrast, serotinous seeds ac- cumulate in the canopy over successive years and then are simultaneously released after a fire and germinate with the following rains (Crawford et al. 2010). In some serotinous species, including our genus of interest (Leucadendron), plants must allocate resources (e.g., water) to the cones for them to stay closed (Cramer and Midgley 2009; Treurnicht et al. 2016), which makes the seed bank viability highly sensitive to adult morbidity.

Extreme climates, associated, for instance, with intense drought or frost, jeopardize adult survival between fires and/or seedling establishment after fire (Enright and Lamont 1992; Jump et al. 2006; Enright et al. 2015). Serotinous nonsprouters display nonoverlapping generations. Because their reproduction relies on a single recruitment event and their seed bank does not persist beyond the death of the parents, they should be vulnerable to extreme climatic events. In contrast, resprouters with an underground seed bank may be less threatened by such events, given their iteroparity and long-lasting seed bank (Orzack and Tuljapurkar 1989; Childs et al. 2010). We therefore hypothesize that serotiny and nonsprouting evolved in association with ecological niches characterized by mild climates with less intense drought and frost (fig. 1a). Furthermore, we hypothesize that plant life histories evolved jointly with fire regimes. We expect resprouters to tolerate shorter mean fire return intervals than nonsprouting species, as the former can better tolerate immaturity risk, that is, fires occurring before first reproduction (Iwasa and Kubo 1997; Ojeda et al. 2005). In contrast, serotinous nonsprouters follow a risky strategy sensitive to both very long and very short fire intervals (Tonnabel et al. 2012). We therefore expect that resprouting should jointly evolve with ecological niches characterized by short, and variable, mean fire intervals (fig. 1b). Finally, we expect serotiny to jointly evolve with niches with lower variance in fire return intervals (fig. $1 b$ ).

The genus Leucadendron (Proteaceae) presents an enticing opportunity to explore the joint evolution of lifehistory traits and ecological niche. Leucadendron harbors a high diversity of such traits as well as many independent transitions among these traits in its phylogenetic history (Tonnabel et al. 2014a). This genus is distributed in a restricted area, the South African fynbos biome, which is known to display important ecological variation in both climate and fire regimes (Schulze 1997; Wilson et al. 2015). The spatial distribution of each Leucadendron species has been fully described in a citizen science project (Rebelo 2001). We also have data on climatic variation in this region and previously published predictions about the variation in fire regimes across the ranges of most species (Merow et al. 2014). To test our hypotheses about how plant lifehistory traits should coevolve with ecological niches, we use a recently published phylogeny for Leucadendron that includes most species in the genus (Tonnabel et al. 2014a). 
a) Climatic niche

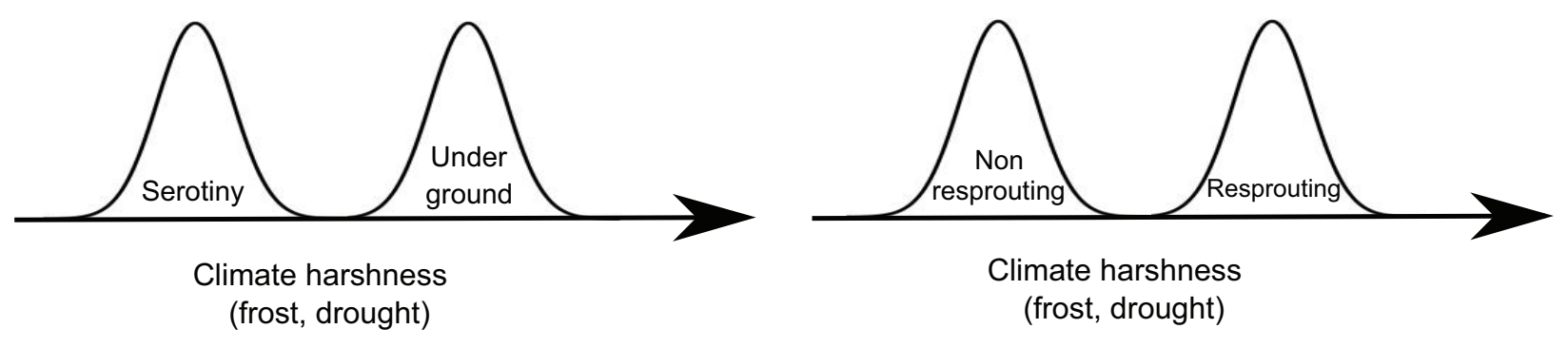

b) Disturbance niche

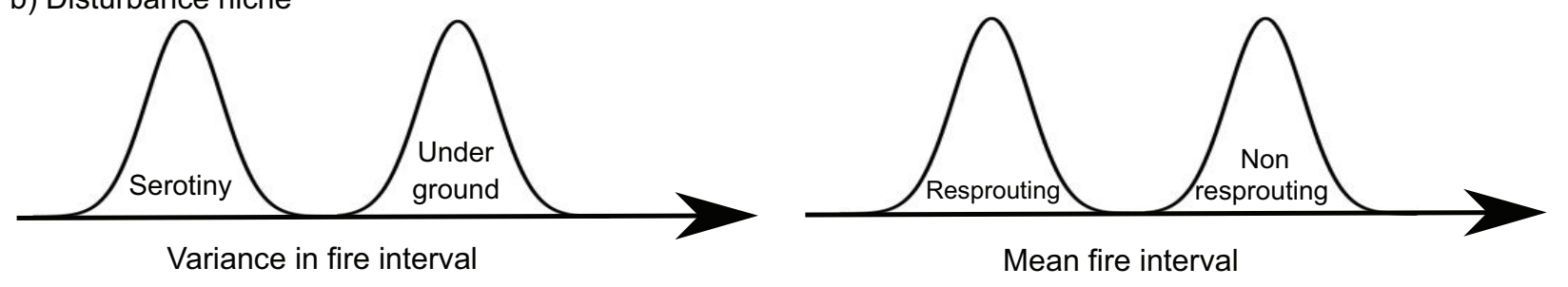

Figure 1: Summary of our hypotheses for the joint evolution of life-history traits with the climate $(a)$ and the fire regime $(b)$ within the species niche. Species with an underground seed bank or able to resprout after fire should be less affected by extreme climatic events and should evolve niches with a harsher optimal climate than serotinous or nonsprouting species, respectively. Species with an underground seed bank should evolve niches with an optimal fire regime less predictable than that of serotinous species. Species able to resprout should evolve niches with higher frequency of fire than those of nonsprouters. Note that mean fire intervals and variance in fire intervals are correlated in our data set.

We apply process-based models of niche evolution and recent comparative approaches that have proven successful in previous investigations of joint evolution of life-history traits and niches (Cooper and Purvis 2010; Boucher et al. 2012; Kostikova et al. 2013; Litsios et al. 2014; Onstein et al. 2016). We evaluate the robustness of our conclusions by explicitly considering uncertainties in the phylogeny, niche values, and reconstructed life-history trait evolution. We also compare our results to simulations where niche evolution is independent of life history, following recent recommendations for these types of analysis (Boettiger et al. 2012; Münkemüller et al. 2015; Silvestro et al. 2015; Cooper et al. 2016). Our analyses provide evidence for an evolutionary association between combinations of life-history traits and niche position along gradients of climate harshness, fire frequency, and their predictability. Finally, we discuss the mechanisms underlying these evolutionary associations and their implications for the evolution of diversity in fireprone ecosystems.

\section{Material and Methods}

\section{Study Group and Phylogenetic Relationships}

Leucadendron $\mathrm{R}$. Br. is a dioecious genus in the Proteaceae that inhabits a biodiversity hotspot known as the Cape Flo- ristic Region (Rebelo 2001). This Mediterranean-climate region covers a range of climatic conditions and fire regimes (Wilson et al. 2010). Fires typically cover large areas, burn most aboveground biomass, and occur, on average, every 10-21 years (Kraaij et al. 2013). Leucadendron probably originated between 28.5 and 30.3 million years ago (Sauquet et al. 2009). Tonnabel et al. (2014a) provided DNA sequence data on nine markers for 81 of the 96 species in the genus. They used eight low-copy nuclear markers designed by Tonnabel et al. (2014c) and Illing et al. (2009), plus the standard internal transcribed spacer region (available in the Dryad Digital Repository: http://dx.doi.org /10.5061/dryad.18g80.1; Tonnabel et al. 2014b) to reconstruct phylogenetic relationships in a maximum likelihood (ML) framework. A chronogram was derived with penalized likelihood rate smoothing (Sanderson 2002).

\section{Life-History Traits}

Species in the genus Leucadendron vary greatly in seed storage traits and the ability of adults to survive fire (Williams 1972; Rebelo 2001). Our focal group includes species that are either serotinous and nonsprouting ( $\mathrm{SN} ; 45.7 \%)$ or serotinous and resprouting (SR; 8.6\%). An additional 42.0\% of the species are nonsprouters with a seed bank stored in the soil (underground seed bank [UN]), while $3.7 \%$ are 
resprouters with an underground seed bank (UR). Data on life-history traits were obtained from the literature (Rebelo 2001; Barker et al. 2004; Tonnabel et al. 2014a; see table A1, available online, for life-history trait codings). Statistical power in comparative analyses increases with the number of independent transitions among traits along the phylogeny. Tonnabel et al. (2014a) showed that transitions from serotiny to underground seed banks and vice versa occurred on average $7.0( \pm 2.1)$ times across the Leucadendron phylogeny. Independent transitions from resprouting to nonsprouting occurred on average $10.4( \pm 4.6)$ times, and the reverse transitions occurred 7.1 ( \pm 2.6 ) times (fig. 2).

\section{Species Distributions and Ecological Niches}

We obtained spatial distributions of our 81 Leucadendron species based on 81,909 occurrences from the Protea Atlas Database (Rebelo 2001). Because of its high spatial and taxonomic resolution, the Protea Atlas Database is a unique tool for studying species distributions (Schurr et al. 2012). For each presence point, we extracted several climatic variables reflecting frost and drought intensities from the WORLDCLIM database (Hijmans et al. 2005) at a spatial resolution of 30 arc seconds and from the South African Atlas of Agrohydrology and Climatology (Schulze 1997) at a spatial resolution of 1 arc second. We selected the variables most directly expressing these climatic constraints, avoiding highly correlated variables (i.e., with absolute values of Spearman correlation coefficients $>0.7$ ). We characterized frost exposure by the number of frost days-the average number of days per year with a minimum temperature lower than $0^{\circ} \mathrm{C}$ (from Schulze 1997). We characterized drought intensity by the mean precipitation of the driest month (from Hijmans et al. 2005).

To characterize disturbance regimes, we used the most recent estimate of the spatial variation in fire return interval (Merow et al. 2014). Merow et al. estimate, for the first time, the distribution of intervals between fires outside nature reserves, allowing us to keep most Leucadendron species in our analyses. Merow et al.'s (2014) analysis combines satellite-derived postfire vegetation recovery trajectories (Wilson 2012) with data on fire return intervals. The latter represent nearly complete coverage from 1980 to 2010, originating from CapeNature and MODIS (moderateresolution imaging spectroradiometer; see van Wilgen et al. 2010; Wilson et al. 2010; de Klerk et al. 2012). Merow et al. (2014) estimated the statistical relationship between postfire vegetation recovery and the distribution of fire return intervals. They later used this same statistical model to estimate the distribution of fire intervals in areas characterized solely by postfire vegetation recovery. However, Merow et al. (2014) estimated spatial variation in only one of the two parameters of the Weibull distribution. Estimated mean fire intervals are thus perfectly correlated with estimated standard deviation in fire intervals. We therefore interpret the mean fire interval predicted by Merow et al. (2014) in different locations both as a proxy inversely related to the frequency of fires and as a proxy for the variance in fire intervals.

Estimates of environmental variables were not available for all populations identified by the Protea Atlas. This led to different sample sizes for our three ecological variables. For the number of frost days, precipitation in the driest month, and mean fire interval, we had 81,81 , and 78 species and 69,609, 70,411, and 40,942 populations, respectively (see table A1 for details). All three ecological variables displayed distinct variation among species (fig. 2): average number of frost days (0-40.5), mean precipitation in the driest month (5.0-56.6 mm), and mean fire return interval (13.8-18.7 years). Spearman correlation coefficients were also below our threshold (between mean precipitation in the driest month and number of frost days, -0.22 ; between this mean precipitation and mean fire return interval, -0.66 ; and between number of frost days and the mean fire return interval, 0.51). We thus performed all subsequent analyses separately for each ecological variable.

\section{Joint Evolution of Ecological Niches and Life-History Traits}

Following several recent studies (e.g., Evans et al. 2011; Litsios et al. 2014; Ogburn and Edwards 2015), we modeled the evolution of species' niche position along different environmental gradients across the phylogeny. In particular, we modeled niche position as a quantitative character along three gradients (variation in frost exposure, drought intensity, and fire frequency). We then compared the relative support for several alternative models describing niche evolution along the phylogeny (table 1). For each ecological variable, we modeled the evolution of niche position (1) at random, (2) toward a single optimum for all species, or (3) toward several optima that depended on ancestral fire-related traits along the branches of the phylogenetic trees (table 1). We then evaluated the relative support for these models by comparing their Akaike weights. We calculated the mean optimal niche position for each combination of life-history traits (i.e., SN, SR, UN, and UR) by averaging these model predictions, weighting each estimate by its Akaike weight. Finally, we investigated whether the resulting differences in optimal niche position among these various combinations of fire-related traits supported our a priori hypotheses. We interpret our results as reflecting a joint evolution between niches and life-history traits. Our analyses, however, do not allow us to discriminate between (1) a scenario where life history would change first and then allow the colonization of a new environment and (2) a scenario where the environment would change first and then 


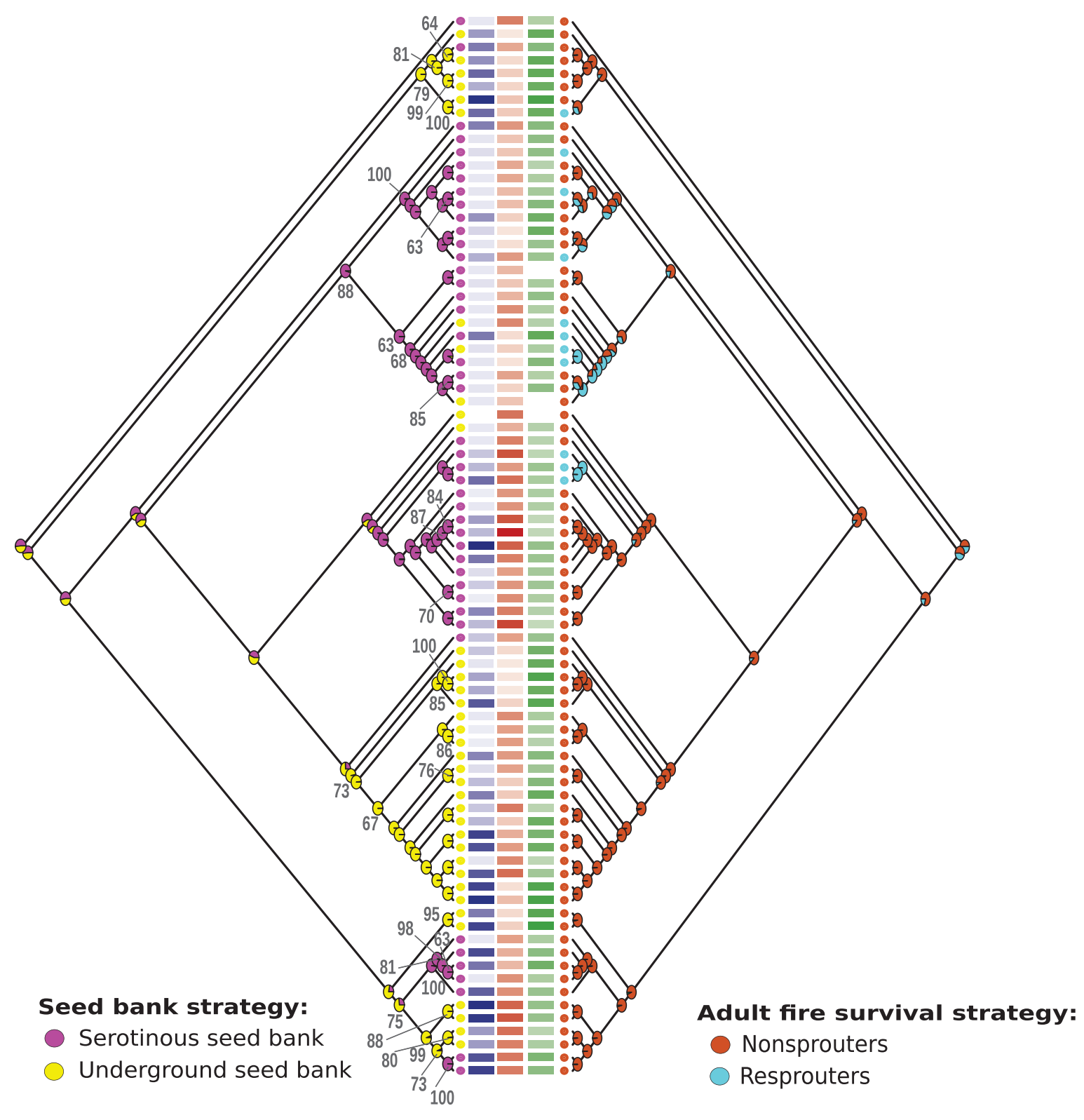

Environmental variable:

\begin{tabular}{|c|c|c|}
\hline 40.5 & 0 & Number of frost days (Nb) \\
\hline & & Precipitation of the driest month $(\mathrm{mm})$ \\
\hline 56.6 & 5 & \\
\hline & & Mean fire interval (years) \\
\hline 18.7 & 13.8 & \\
\hline
\end{tabular}

Figure 2: Maximum likelihood phylogeny for the genus Leucadendron, showing life-history traits and environmental niche values for 81 extant species. Pie charts on internal nodes show the estimation of ancestral life-history traits based on best-fitting Markov models. Phylogenetic node support is expressed by bootstrap values, indicated on the left-hand tree when greater than 60. Species mean environmental values, averaged over all occurrences of each species, are indicated as follows: darker blue corresponds to higher numbers of frost days (i.e., intensity of frost), darker red indicates higher precipitation of the driest month (i.e., inversely related to the intensity of drought), and darker green corresponds to less frequent fires. 
Table 1: Description of models of quantitative traits evolution used to compare various scenarios of niche evolution

\begin{tabular}{|c|c|c|}
\hline Model type, name & Parameters & Biological interpretation \\
\hline \multicolumn{3}{|c|}{ Brownian motion $(\mathrm{d} X(t)=\sigma \cdot \mathrm{d} B(t))$ : } \\
\hline $\mathrm{BM}$ & $\sigma_{\mathrm{SN}, \mathrm{SR}, \mathrm{UN}, \mathrm{UR}}$ & $\begin{array}{l}\text { Environmental drift or selection under fluctuating } \\
\text { environments }\end{array}$ \\
\hline $\begin{array}{l}\text { Ornstein-Uhlenbeck }(\mathrm{d} X(t)=\alpha \\
\qquad(\theta-X(t)) \cdot \mathrm{d} t+\sigma \cdot \mathrm{d} B(t))\end{array}$ & $\sigma_{\mathrm{SN}, \mathrm{SR}, \mathrm{UN}, \mathrm{UR}}$ and & \\
\hline OUS & $\theta_{\mathrm{SN}}=\theta_{\mathrm{SR}}=\theta_{\mathrm{UN}}=\theta_{\mathrm{UR}}$ & $\begin{array}{l}\text { Selection toward an optimum regardless of the trait } \\
\text { combination }\end{array}$ \\
\hline OUM1 & $\theta_{\mathrm{SN}, \mathrm{SR}} \neq \theta_{\mathrm{UN}, \mathrm{UR}}$ & $\begin{array}{l}\text { Serotinous species are more sensitive to stressful niche } \\
\text { values than species with underground seed banks }\end{array}$ \\
\hline OUM2 & $\theta_{\mathrm{SN}, \mathrm{UN}} \neq \theta_{\mathrm{SR}, \mathrm{UR}}$ & $\begin{array}{l}\text { Nonsprouting species are more sensitive to stressful } \\
\text { niche values than resprouting species }\end{array}$ \\
\hline OUM3 & $\theta_{\mathrm{SN}} \neq \theta_{\mathrm{SR}} \neq \theta_{\mathrm{UN}} \neq \theta_{\mathrm{UR}}$ & $\begin{array}{l}\text { Each combination of fire-related traits evolved toward } \\
\text { different optimal niche values }\end{array}$ \\
\hline OUM4 & $\theta_{\mathrm{SN}} \neq \theta_{\mathrm{SR}, \mathrm{UN}} \neq \theta_{\mathrm{UR}}$ & $\begin{array}{l}\text { Serotinous nonsprouting species and resprouting spe- } \\
\text { cies with underground seed banks are extreme com- } \\
\text { binations that are respectively more and less sensitive } \\
\text { to stressful niche values }\end{array}$ \\
\hline OUM5 & $\theta_{\mathrm{SN}} \neq \theta_{\mathrm{SR}, \mathrm{UN}, \mathrm{UR}}$ & $\begin{array}{l}\text { Serotinous nonsprouting species are extreme combina- } \\
\text { tions that are more sensitive to stressful niche values }\end{array}$ \\
\hline OUM6 & $\theta_{\mathrm{SN}, \mathrm{SR}, \mathrm{UN}} \neq \theta_{\mathrm{UR}}$ & $\begin{array}{l}\text { Resprouting species with underground seed banks are } \\
\text { extreme combinations that are less sensitive to } \\
\text { stressful niche values }\end{array}$ \\
\hline OUM7 & $\theta_{\mathrm{SN}, \mathrm{SR}} \neq \theta_{\mathrm{UN}} \neq \theta_{\mathrm{UR}}$ & $\begin{array}{l}\text { Serotinous species are more sensitive to stressful niche } \\
\text { values than nonsprouting species with underground } \\
\text { seed bank, which are in turn less sensitive than } \\
\text { resprouting species with underground seed banks }\end{array}$ \\
\hline OUM8 & $\theta_{\mathrm{SN}} \neq \theta_{\mathrm{SR}} \neq \theta_{\mathrm{UN}, \mathrm{UR}}$ & $\begin{array}{l}\text { Serotinous nonsprouting species are more sensitive to } \\
\text { stressful niche values than serotinous resprouting } \\
\text { species, which are in turn less sensitive than species } \\
\text { with underground seed banks }\end{array}$ \\
\hline OUM9 & $\theta_{\mathrm{SN}, \mathrm{UN}} \neq \theta_{\mathrm{SR}} \neq \theta_{\mathrm{UR}}$ & $\begin{array}{l}\text { Nonsprouting species are more sensitive to stressful } \\
\text { niche values than serotinous resprouting species, } \\
\text { which are in turn less sensitive than resprouting } \\
\text { species with underground seed banks }\end{array}$ \\
\hline OUM10 & $\theta_{\mathrm{SN}} \neq \theta_{\mathrm{UN}} \neq \theta_{\mathrm{SR}, \mathrm{UR}}$ & $\begin{array}{l}\text { Serotinous nonsprouting species are more sensitive to } \\
\text { stressful niche values than nonsprouting species with } \\
\text { underground seed banks, which are in turn less sen- } \\
\text { sitive than resprouting species }\end{array}$ \\
\hline
\end{tabular}

Note: In the equations, $\mathrm{d} X(t)$ corresponds to the variation of the quantitative trait of interest (i.e., the niche variable), $\mathrm{d} B(t)$ is a random deviate of mean $0, \sigma$ is a parameter corresponding to the strength of drift, $\theta$ is the optimum niche value, and $\alpha$ is the strength of the attraction toward this optimum. Subscripts of $\theta$ parameters describe the combinations of life-history traits for which such parameter is estimated. The test of our three hypotheses is based on the comparison of the estimated $\theta$ values for different combinations of fire-related traits of selected models: $\mathrm{SN}=$ serotinous nonsprouting species; SR $=$ serotinous resprouting species; UN = underground seed bank nonsprouting species; UR = underground seed bank resprouting species.

select for a different life history. Both scenarios can be envisioned.

The Brownian motion (BM) model describes the unconstrained evolution of niche position along the phylogenetic branches as a random walk with a constant rate $\sigma$ but no preferred direction (table 1). It was used to model the random evolution of niche position (case 1 above). OrnsteinUhlenbeck models (OU; table 1) combine the stochastic component of a BM model with a parameter formalizing attraction $\alpha$ toward an optimal niche position $\theta$ (Hansen 1997). In the case of multioptima OU (OUM) models, species with different characteristics (combinations of lifehistory traits) can be attracted toward distinct $\theta$ optima. OU models allow translation of hypotheses regarding adaptation to different selective regimes into explicit models (Butler and King 2004). Although OU models are usually aimed at describing stabilizing selection, the patterns they generate can also result from constraints, such as bound- 
aries on trait values (Boucher et al. 2014). We used OU models with one or several optima to model cases 2 and 3 noted above.

In total, we compared 12 models describing the evolution of niches: one BM and $11 \mathrm{OU}$ models of evolution (table 1; fig. 3). Our BM model included a single evolutionary rate parameter $\sigma$ for all species (table 1), and all OU models included only one value for $\sigma$ and $\alpha$, common to all species (table 1). Our first OU model (OUS) included a single parameter $\theta$ for all species, describing the optimal niche position. Multioptima OU models (OUM1-10) comprised two to four $\theta$ parameters corresponding to different niche posi- tion optima for different combinations of fire-related traits. Each model thus corresponds to a different scenario of joint evolution between fire-related traits and niches (table 1). Life-history theory allows predictions contrasting the niche evolution for different adult survival strategies or for different seed bank types (fig. 1). However, we lack precise predictions about how specific combinations of adult and seed traits affect niche evolution. While serotinous nonsprouters appear to adopt the most risk-averse strategy, it is unclear whether different forms of bet-hedging strategy (underground seed bank vs. resprouting) or their combination allows colonization of different niches. We therefore

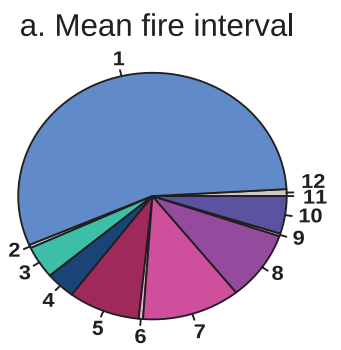

b. Number of frost days

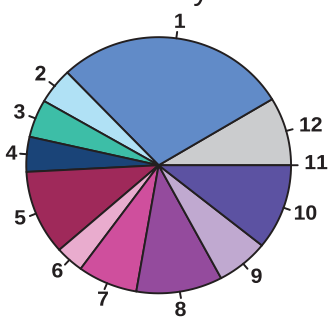

c. Precipitation of the driest month

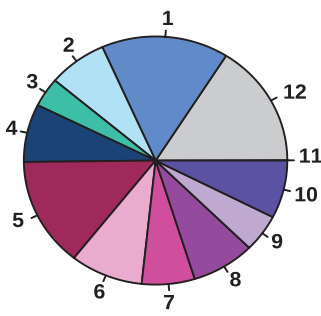

\section{d. Simulated BM}
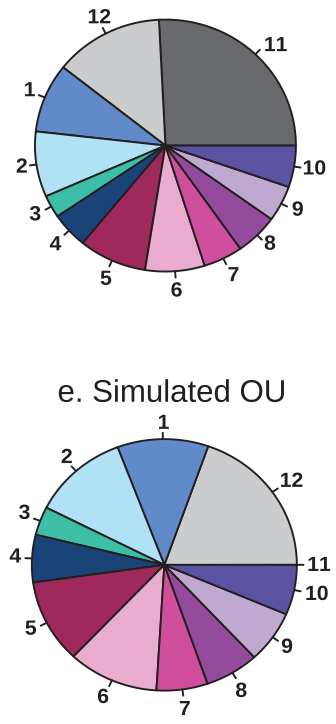

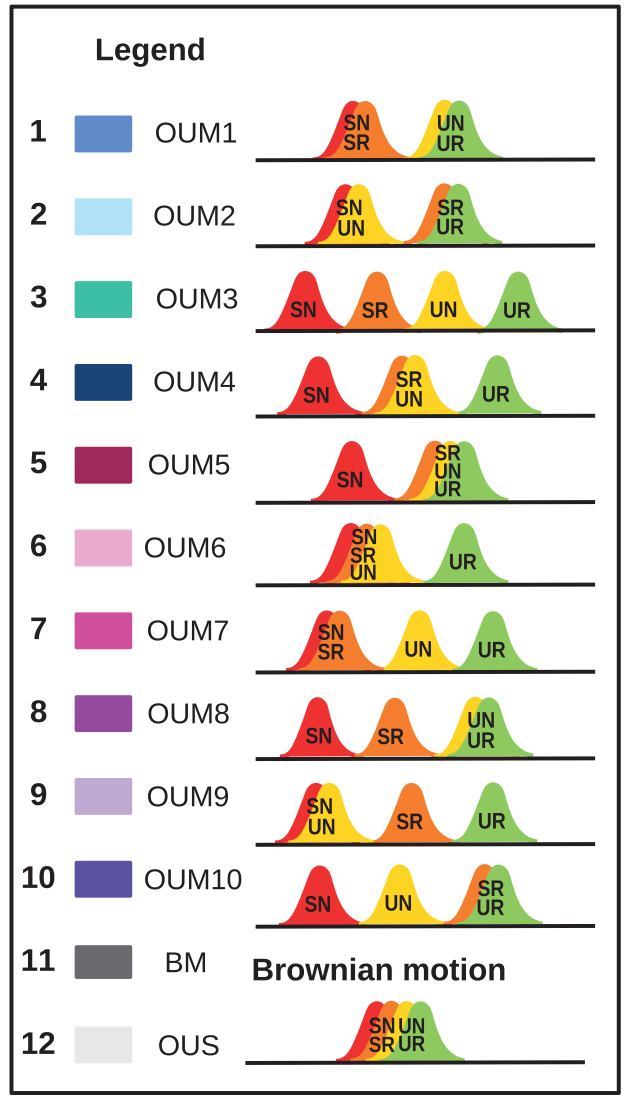

Figure 3: Mean Akaike weights of the 12 models of evolution estimated on our three environmental variables of interest: mean fire interval $(a)$, number of frost days $(b)$, and precipitation of the driest month $(c)$. The hypotheses behind each model of niche evolution are schematically presented in the box to the right (see also table 1), showing how optimal niches vary, depending on life-history trait combinations ( $\mathrm{SN}=$ serotinous nonsprouting; $\mathrm{SR}=$ serotinous resprouting; $\mathrm{UN}=$ underground nonsprouting; $\mathrm{UR}=$ underground resprouting). For instance, model OUM1 assumes that serotinous species have a different optimal niche position than species with an underground seed bank but that resprouting does not affect optimal niche position. The fit of the 12 models of evolution was also estimated with the mean Akaike weight for simulated environmental values and a Brownian motion $(\mathrm{BM} ; d)$ or a single-optimum Ornstein-Uhlenbeck (OU; $e$ ) process. To simulate the BM and OU processes, we estimated the parameters of the $\mathrm{BM}(\sigma)$ and $\mathrm{OU}(\sigma, \alpha$, and $\theta)$ models, using the maximum likelihood tree, the marginal ancestral reconstruction of the life-history traits, and the mean value of the environment per species separately for each environmental variable. The results shown in $d$ and $e$ are the ones generated with the parameters of the BM and OUS models estimated for the mean fire interval (patterns were similar for all simulated environmental variables; see fig. A1, available online). OUM and OUS $=$ multioptima and single-optimum OU models, respectively. 
chose to examine a large diversity of models making different assumptions about the joint evolution of the niche and combinations of adult and seed bank traits (table 1; fig. 3 ). Hereafter, the subscripts of $\theta$ parameters denote the combinations of fire-related traits for which they were estimated. For example, the OUM1 model had two different optima $\left(\theta_{\mathrm{SN}, \mathrm{SR}}\right.$ and $\left.\theta_{\mathrm{UN}, \mathrm{UR}}\right)$, contrasting species with serotinous and ones with underground seed banks regardless of their adult fire survival strategy. Conversely, the OUM2 model contained two $\theta$ parameters $\left(\theta_{\mathrm{SN}, \mathrm{UN}} ; \theta_{\mathrm{SR}, \mathrm{UR}}\right)$ contrasting nonsprouting species and resprouting ones, regardless of their seed storage strategy. Brief biological interpretations of the 10 scenarios appear in table 1 .

\section{Accounting for Sources of Uncertainty}

We accounted for different sources of uncertainty (de Villemereuil et al. 2012) when comparing the relative support for the 12 models of niche evolution. Phylogenetic uncertainty was accounted for with a set of 100 bootstrap trees. We generated 100 ancestral-state estimations of fire-related traits per bootstrap tree, using Markov models (see Tonnabel et al. 2014a) to account for uncertainty in ancestralstate estimation. Most comparative studies of niche evolution ignore the variability in environmental conditions within the species range. Thus, we also compared the support of our models by using either the species niche position (i.e., the mean of the environmental variable across all occurrences of the species) or a resampling procedure of environmental values per species at the tree tips (i.e., randomly choosing one population per species and extracting its environmental value; Boucher et al. 2012). For each ecological variable, we examined the support of our 12 models of evolution 10,000 times by randomly choosing one bootstrap tree, one reconstruction of ancestral life-history traits, and either the mean ecological value per species or one value drawn at random from the species range.

\section{Exploration of the Relative Support and Estimation of Niche Optima}

For each iteration of the resampling procedure, we calculated the Akaike weight of each model $i$, following equation (1), where $j$ ranges from 1 to the total number of models compared $k(k=12$, in our case $)$ and $\mathrm{AICc}_{\min }$ is the AICc (Akaike information criterion corrected for small sample sizes) of the model that yielded the lowest AICc value (Burnham and Anderson 2002):

$$
w_{i}=\frac{\exp \left(-(1 / 2)\left(\mathrm{AICc}_{i}-\mathrm{AICc}_{\min }\right)\right)}{\sum_{j=1}^{k}\left[\exp \left(-(1 / 2)\left(\mathrm{AICc}_{j}-\mathrm{AICc}_{\min }\right)\right)\right]} .
$$

The Akaike weight is thus the probability that model $i$ is the best model for the observed data, given the candidate set of models (Johnson and Omland 2004). Thus, for each resampling iteration, we obtained one Akaike weight, $w_{i}$, for each of our 12 models. We then averaged each model Akaike weight across all resampling iterations to obtain the mean Akaike weight of the model. We further estimated the optimum niche position per combination of life-history strategies (i.e., SN, SR, UN, and UR) by calculating a weighted average of parameter estimates $\theta$ across all $(R=11)$ of our OU models:

$$
\dot{\theta}=\frac{\sum_{i=1}^{R} w_{i} \hat{\theta}_{i}}{\sum_{i=1}^{R} w_{i}}
$$

We calculated these weighted average estimates of niche position for each trait combination and resampling iteration and then averaged these across all resampling iterations. We further provide the standard deviation of these estimates across resampling iterations.

\section{Validating Our Model Comparison Approach}

Several recent studies have highlighted potential pitfalls of comparing BM and OU models. For instance, small tree sizes and errors in phylogenetic reconstructions or high errors in the quantitative character estimation can lead to an unacceptable rate of selection of OU models when a BM process is simulated (Boettiger et al. 2012; Silvestro et al. 2015; Cooper et al. 2016). Inspired by these studies, we performed several controls to check the robustness of our biological inferences from model comparisons. First, we evaluated the support of our 12 models of evolution, using simulated niche positions and following the approach of Boettiger et al. (2012). Our simulations assumed that niche position evolved as a neutral quantitative character or that selection on niche position was unconstrained by life history. The rationale was to check whether the relative support of multioptima OU models was higher for observed niche positions than for niche positions simulated under alternative models. To do so, we first estimated the parameters of the BM model $(\sigma)$ and of a single-optimum OU model $(\sigma, \alpha$, and $\theta)$, using the ML tree and the mean value of each of our three ecological variables per species. We then used these estimated parameters to simulate 1,000 niche positions for a BM model or a single-rate OU model, using the ML tree. We then examined the fit of the 12 models of evolution to these simulated niche data, using the resampling procedure based on bootstrap trees and ancestraltrait reconstruction. To determine whether our multioptima OU (OUM) models had stronger support than a singleoptimum OU model or a BM model, we compared the re- 
sulting mean Akaike weight with the ones obtained with simulated niche data. Second, we checked that $\alpha$ values, expressing the strength of attraction toward $\theta$, were not so small that OU models would be actually indistinguishable from BM models (Hansen 1997; Münkemüller et al. 2015; Cooper et al. 2016). That is, we estimated the "phylogenetic half-time" $\left(t_{1 / 2}\right)$, defined as the time needed for a species to evolve halfway toward its new expected optimum niche value:

$$
t_{1 / 2}=\frac{\ln 2}{\alpha}
$$

We checked to ensure that the phylogenetic half-time was smaller when we fitted models on our ecological variables than when we used data simulated under a BM model (attesting to a stronger attraction toward an optimum than expected at random). Third, we investigated whether error in the estimation of the niche position could affect our results, as suggested by Silvestro et al. (2015). We compared the relative support of our 12 models of evolution when error in estimating the niche position was accounted for and when it was not, using 1,000 iterations of the resampling procedure to bootstrap trees and ancestral-state reconstructions. We performed simulations of BM and OU models and the fit of alternative models, using the OUwie package (Beaulieu et al. 2012) implemented in R ( R Development Core Team 2012).

\section{Results}

\section{Support for Different Niche Evolution Models}

We found a clear signal for joint evolution of seed bank type and niche position along a gradient of mean fire interval. When fitted to observed mean fire intervals, the OUM1 model had the highest mean Akaike weight (i.e., 0.56; fig. 3a), far higher than those for niches simulated under the BM and OUS models (fig. $3 d, 3 e$ ). The OUM1 model differentiates the optimal niche positions of serotinous species and species with an underground seed bank, regardless of their adult fire survival strategy $\left(\theta_{\mathrm{SN}, \mathrm{SR}} \neq \theta_{\mathrm{UN}, \mathrm{UR}}\right)$. One other model, OUM7, served to differentiate serotinous nonsprouting species with underground seed banks from resprouting species with underground seed banks $\left(\theta_{\mathrm{SN}, \mathrm{SR}} \neq\right.$ $\left.\theta_{\mathrm{UN}} \neq \theta_{\mathrm{UR}}\right)$. This model had a mean Akaike weight $(0.12)$ almost twice as high as those for niches simulated under the OUS model (compare fig. $3 a$ to fig. $3 d, 3 e$ ). Both the random BM and single-optimum OUS models had very small mean Akaike weights $\left(<10^{-5}\right.$ and $10^{-2}$, respectively), contrary to the simulated niche data (compare fig. $3 a$ to fig. $3 d, 3 e$ ). Support for the different evolutionary models was similar whether we simulated the evolution of niche position along gradients of mean fire interval, number of frost days, or precipitation of the driest month (compare fig. $3 d, 3 e$ to fig. A1; figs. A1-A5 are available online).

Our data support the hypothesis that niche position along a gradient of exposure to frost jointly evolved with life history in Leucadendron. When fitted to the observed number of frost days, the OUM1 model $\left(\theta_{\mathrm{SN}, \mathrm{SR}} \neq \theta_{\mathrm{UN}, \mathrm{UR}}\right.$, differentiating serotinous and underground seed bank strategies) had the highest mean Akaike weight (i.e., 0.29; fig. $3 b$ ). The two next-best models, namely, OUM8 $\left(\theta_{\mathrm{SN}} \neq \theta_{\mathrm{SR}} \neq\right.$ $\left.\theta_{\mathrm{UN}, \mathrm{UR}}\right)$ and OUM10 $\left(\theta_{\mathrm{SN}} \neq \theta_{\mathrm{UN}} \neq \theta_{\mathrm{SR}, \mathrm{UR}}\right)$, had mean Akaike weights of $\sim 0.1$, almost twice as high as those for simulated niches under OUS and BM models (compare fig. $3 b$ to fig. $3 d, 3 e$ ). The BM model had almost no support (mean Akaike weight $<10^{-4}$ ), in contrast to the simulated niche data (compare fig. $3 b$ and fig. $3 d$ ). The singleoptimum OUS model had slightly higher support (mean Akaike weight of 0.09) but still far less than the simulated single-optimum OUS model (i.e., 0.19; compare fig. $3 b$ and fig. $3 e$ ).

For precipitation in the driest month, we found no evidence of joint evolution of niche position along this gradient with life history (fig. $3 c$ ). As before, the BM model had no support (mean Akaike weight $<10^{-3}$; compare fig. $3 c$ to fig. $3 d$ ). Here, however, the single-optimum OUS model was well supported, with a mean Akaike weight (0.16; fig. $3 c$ ) similar to that obtained for niche data simulated with an OUS model (0.18; compare fig. $3 c$ and $3 e$ ). Two other models, OUM1 $\left(\theta_{\mathrm{SN}, \mathrm{SR}} \neq \theta_{\mathrm{UN}, \mathrm{UR}}\right)$, which differentiates serotinous and underground seed bank strategies, and OUM5 $\left(\theta_{\mathrm{SN}} \neq \theta_{\mathrm{SR}, \mathrm{UN}, \mathrm{UR}}\right)$, which differentiates serotinous nonsprouters from all others, had comparable Akaike weights of 0.16 and 0.14 , respectively. These weights also resembled those of models using niches simulated under OUS simulations (compare fig. $3 c$ and $3 e$ ). Overall, the relative support of the different models was quite similar to that obtained for simulated niches (fig. $3 c$ compared to fig. $3 e$ ).

The estimated phylogenetic half-times, $t_{1 / 2}$, estimated by OU models fitted to observed ecological variables ranged from 0.02 to 0.1 . These values are orders of magnitude lower than those for simulated niche positions under BM models (ranging from 2.46 to $3.99 \times 10^{7}$ ).

For all three ecological variables, the relative support of our 12 models of evolution was similar whether standard error in the estimation of the niche position per species was accounted for or not (fig. A2). This likely reflects the high number of locations per species and consequent low measurement error on niche positions in our data. Mean standard error per species across our data set was 0.07 years for mean fire interval, 0.45 days for the number of frost days, and $0.23 \mathrm{~mm}$ for the precipitation of the driest month. Resampling ecological values within species thus had only small effects on the relative support of our 12 models of niche evolution (fig. A3). 


\section{Optimal Niche Position and Life-History Traits}

Optimal niche position estimated across all trees and ancestral-state reconstructions for different life-history strategies showed that serotinous species evolved niches characterized by lower mean fire intervals than species with underground seed banks (fig. 4a). For species with an underground seed bank, resprouters displayed slightly lower optimal mean fire return intervals than nonsprouters (fig. 4a). Conversely, for serotinous species, resprouters and nonsprouters displayed similar optimal mean fire return intervals (fig. 4a). Serotinous nonsprouting species evolved niches with fewer frost days, compared to all other lifehistory strategies that could be grouped in one category displaying similar optimal niche positions relative to frost exposure (fig. 4b). The optimal precipitation of the driest month did not differ significantly across life histories (fig. 4c). For all three ecological variables, the variance associated with estimates of optimal niche position was higher for resprouters than for nonsprouters (fig. 4).
Accounting for the standard error of the estimation of the niche position per species or resampling ecological values per species only slightly changed the estimations of the optimal niche positions (fig. A4). However, the variance associated with estimates of mean precipitation in the driest month increased considerably when ecological values were resampled (fig. A4f).

\section{Discussion}

Our macroevolutionary analysis of correlated evolution among niches and traits in the genus Leucadendron allowed us to test several predictions of life-history theory. First, iteroparous life cycles should better buffer plants against environmental variation affecting the success of reproduction and juvenile recruitment (Charnov and Schaffer 1973; Schaffer 1974; Orzack and Tuljapurkar 1989). Picking up on our analogy of resprouters versus nonsprouters and iteroparous versus semelparous life-history strategies (Pausas a)

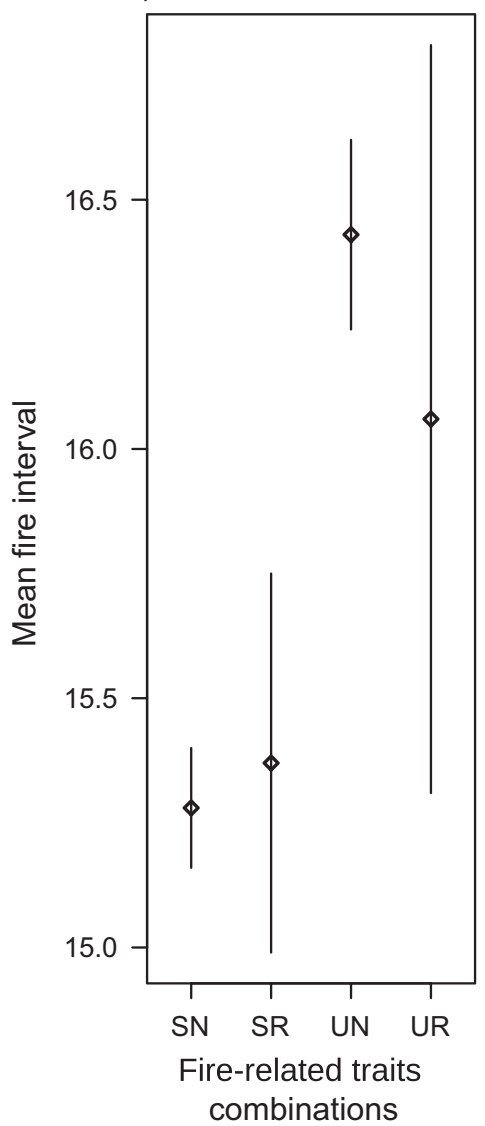

b)

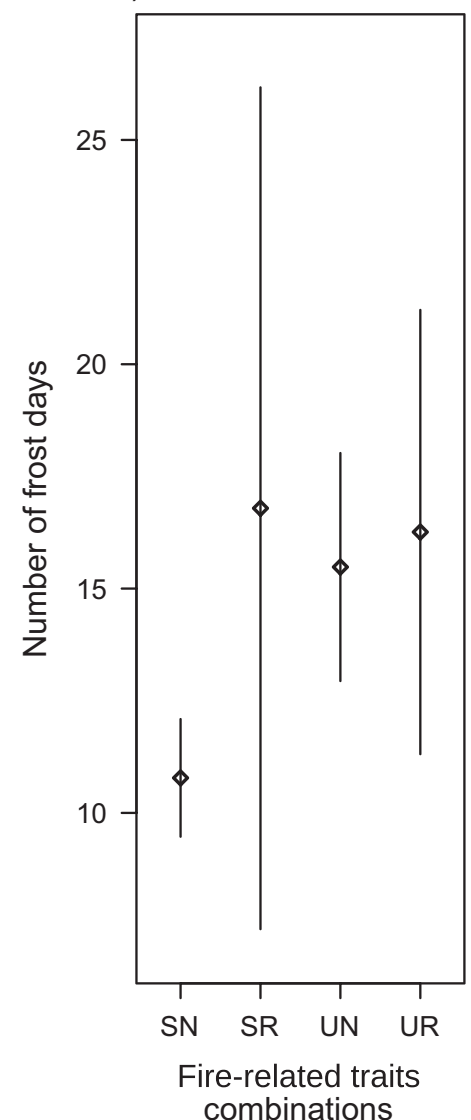

c)

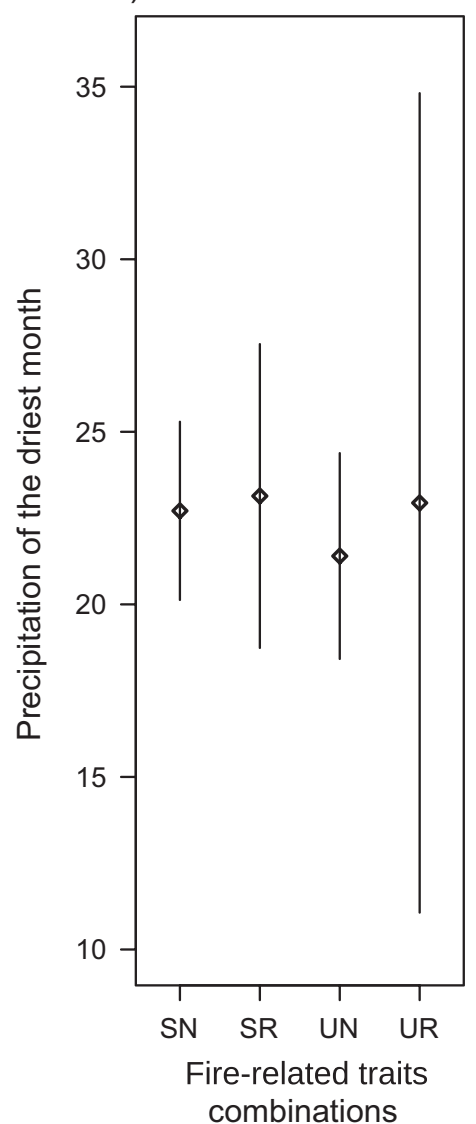

Figure 4: Optimal ecological-niche position estimates for different combinations of life-history traits. Estimates for optima result from Akaike weight averaging using corrected Akaike information criterion (AICc) values of our 11 Ornstein-Uhlenbeck models. SN $=$ serotinous nonsprouting; $\mathrm{SR}=$ serotinous resprouting; $\mathrm{UN}=$ underground nonsprouting; UR $=$ underground resprouting. 
and Keeley 2014), which is made possible by the fact that recruitment mainly happens after fires in fire-prone ecosystems, the evolution of resprouting should allow the colonization of environments with highly variable recruitment. Second, seed banks persisting over several fire cycles and beyond the death of their parents should act to buffer environmental variation, allowing species with this trait to be less sensitive to conditions jeopardizing recruitment and adult survival (Childs et al. 2010). The evolution of underground seed banks (compared to canopy-stored seed banks via serotiny) should therefore allow species to colonize environments with less predictable fire intervals and harsher climates. Our results partly support these predictions. In the history of Leucadendron, the evolution of an alternate seed bank type is associated with the evolution of different fire regimes. Both adult fire survival and underground seed banks evolved jointly with niches characterized by greater exposure to frost. Finally, contrary to our expectation, the evolution of niches with different summer drought intensities was not associated with the evolution of different life-history strategies.

\section{Joint Evolution of Fire-Related Traits and Fire Regimes}

To our knowledge, our study is the first to demonstrate a macroevolutionary association between plant life-history traits and quantitative variation in the fire regimes. $\mathrm{He}$ et al. (2012) previously showed, in the genus Pinus, that serotiny evolved with the appearance of crown fires. We here report that variation in fire frequency has shaped the evolution of seed bank types in Leucadendron. The joint evolution of serotiny and shorter mean fire intervals may have arisen because long fire intervals are predicted to select against serotiny (Enright et al. 1998a, 1998b; Tonnabel et al. 2012; see also Hernández-Serrano et al. 2013 for microevolutionary empirical evidence). Indeed, in Leucadendron, serotinous individuals need to stay alive until the next fire to reproduce, unlike individuals producing an underground seed bank. However, short interfire intervals that allow fire to recur before sexual maturity would also select against serotinous nonsprouters (Tonnabel et al. 2012). This prediction is consistent with empirical observations that short fire intervals negatively affect these species (Enright et al. 2014). Characteristics of the Weibull distribution used to model fire return in our fire niche data set (Merow et al. 2014) imply that greater mean fire return intervals are associated with less predictability in fire return. Our finding is thus consistent with the predictions of several models, showing that lower levels of serotiny evolve when fire regimes become unpredictable (Enright et al. 1998a, 1998b; Tonnabel et al. 2012). This covariation makes it difficult to disentangle the effects of fire frequency and variation in fire return intervals on life-history evolution.
We hypothesized that resprouters should better tolerate shorter fire intervals than nonsprouters because, by surviving fires, they are less prone to "immaturity risks." While this hypothesis was supported for species with an underground seed bank, we did not find support for it in serotinous taxa. The uncertainty associated with niche evolution in resprouters was large (fig. 4a). Theoretical studies predict that relative investment in storage for regrowth should be maximized at some intermediate disturbance frequency (Iwasa and Kubo 1997). Indeed, fires that are too frequent do not allow plants to accumulate enough resources to reproduce between fires. Interestingly, studies relating community composition to disturbance frequency have also found mixed results concerning resprouters (Lloret et al. 2005; Vilà-Cabrera et al. 2008; Enright et al. 2014; Clarke et al. 2015).

\section{Joint Evolution of Life-History Traits and Climatic Preferences}

Our study is the first to report an evolutionary association between frost exposure and fire-related traits. Mediterraneantype fire-prone ecosystems occur in geographical areas with mild winters, where the impact of frost could be underappreciated (but see Langan et al. 1997 for evidence that frost limits species distribution in chaparral shrubs). Our analysis reveals both significant variation in frost exposure among Leucadendron species and associations between frost exposure and the evolution of life-history traits in Mediterranean-climate ecosystems. The evolutionary association we found between frost avoidance and the serotinous nonsprouting strategy could reflect the variety of possible consequences of frost on the life cycle of plants in fire-prone environments. These include (1) reducing seedling establishment, (2) decreasing adult plant survival between fires (Tonnabel et al. 2012 predict effects of reduced adult survival on the evolution of serotiny), and (3) cone opening of serotinous individuals under conditions that disfavor recruitment (Treurnicht et al. 2016).

Like frost, drought can compromise seedling recruitment, adult survival between fires, and the ability of plants to maintain cones in the canopy (Treurnicht et al. 2016; but see West et al. 2012). Consistent with this idea, Litsios et al. (2014), using a comparative analysis similar to ours, found that nonsprouting Restionaceae evolved preferences for colder and less seasonal climates with less intense summer drought, relative to resprouting species. Contrary to our expectation, the intensity of summer droughts within species' ranges did not appear to affect the evolution of fire-related life-history traits in Leucadendron. Although we performed analyses of mean precipitation at various times of year, no values displayed a clear pattern of evolv- 
ing jointly with fire-related life-history traits (results not shown). The relationship between exposure to drought and the evolution of resprouting may be complex. Resprouters have a competitive advantage when regrowth is rapid after disturbance (see Iwasa and Kubo 1997 for theoretical predictions) and not limited by water. Accordingly, Pausas and Keeley (2014) argued that the evolution of nonsprouters is generally associated with aridification of ecosystems.

Our findings are consistent with the idea that riskier semelparous-like strategies with nonoverlapping generations (i.e., serotinous nonsprouters) are disfavored when extreme environmental conditions compromise juvenile recruitment. Our study thus adds to the literature suggesting that life-history evolution can facilitate or constrain the colonization of environments with extreme climates (e.g., Boucher et al. 2012; Kostikova et al. 2013; Litsios et al. 2014; Ogburn and Edwards 2015). Interestingly, in our case, it is the combination of fire-related traits affecting both adult and seed survival after fire that affects evolution of the climatic niche. Underground seed banks and resprouting can be interpreted as nonexclusive mechanisms of bet hedging. Either mechanism seems sufficient to allow species to colonize sites with greater exposure to frost.

\section{Robustness of Conclusions}

Inferences about evolution of quantitative variables along phylogenies, such as niche position here, derived from model comparisons can suffer from biases due, for instance, to measurement error in the characters or in the reconstruction of phylogenies (Boettiger et al. 2012; Silvestro et al. 2015; Cooper et al. 2016). Here, we thoroughly checked for these biases by (1) explicitly considering different sources of uncertainty in our resampling procedure, (2) averaging different model predictions on the basis of their support rather than considering only the model with the highest support, and (3) confronting the support for various models on the basis of observed niche data and simulated results that assumed that niche evolution does not depend on life-history traits. This should make our conclusions robust. However, the many models compared and the large number of parameters associated with various trait combinations in these models limited our ability to explore more complex models.

In our analyses, we did not consider how the evolution of different life histories could affect diversification rates through their effects on generation time and possibly extinction and speciation rates (e.g. Smith and Beaulieu 2009; Schnitzler et al. 2011; Kostikova et al. 2013; Litsios et al. 2014). Different rates of diversification, in turn, could alter the reconstruction of ancestral trait values $(\mathrm{Ng}$ and Smith 2014). We tested the assumption that diversification rates are unrelated to life-history traits (see fig. A5) by comparing models of life-history trait evolution that varied in their assumptions about trait-dependent extinction and speciation rates. We found no effect of seed bank type on diversification (fig. A5). Results were more ambiguous for the effect of resprouting. We found no support for different diversification rates when using the maximum likelihood tree but more frequent support for models assuming different speciation rates in resprouters versus nonsprouters when using bootstrap trees (fig. A5). Overall, our results concerning the joint evolution of seed bank types and niches should be robust to this issue. Results concerning how resprouters evolve, which show some uncertainty, should be considered with more caution.

\section{Conclusions}

In the history of Leucadendron, canopy seed banks coevolved with niches characterized by predictable fire regimes. Life cycles with nonoverlapping generations, combining a canopy seed bank and the inability to resprout after fire, evolved together with ecological niches with milder climates. Disturbance regimes and extreme climatic events have thus shaped the evolution of alternative life histories in this genus, supporting predictions of life-history theory. Several researchers have proposed that the high species diversity in the Cape region, relative to similar regions, reflects the high climatic heterogeneity associated with its complex topography (e.g., Litsios et al. 2014; Linder and Verboom 2015). Some authors have also claimed that fire dynamics, more than climate, have influenced South African vegetation and its diversity (e.g., Bond et al. 2003). Our results support both of these ideas. The evolution of an extraordinary diversity of life histories and functional traits in the South African fynbos is related to the variability of both climates and fire regimes in this region. Preserving this heterogeneity of ecological conditions, which fuels ecological and evolutionary processes in the short and long terms, should therefore be a goal of conservation policy (Cowling and Pressey 2001; Olivieri et al. 2016). Finally, our study illustrates how lifehistory evolution theory helps to predict aspects of the joint diversification of ecological niches and functional traits, connecting fields of ecology and evolution that are rarely integrated (e.g., Evans et al. 2011; Mesquita et al. 2016). This improves our understanding of current and future patterns of biodiversity as both climate and disturbance regimes change under the pressure of anthropogenic activities (Wilson et al. 2015).

\section{Acknowledgments}

In memoriam: Isabelle Olivieri initiated the work of our group on the evolutionary underpinnings of the extraordi- 
nary diversity of life history in the fynbos. We are grateful for this and for so many other things that she transmitted to us. For helpful discussions, we thank Sébastien Lavergne, Agnès Mignot, Isabelle Olivieri, Adam Wilson, Jeremy Midgley, Tony Rebelo, Daniele Silvestro, Joern Pagel, and John Pannell. We warmly thank Don Waller for his careful editing of our manuscript and two reviewers for their helpful comments. This work was supported by a PhD grant of the Ministry of Research and Higher Education to J.T., a grant from the Agence National pour la Recherche project "Evorange" (ANR-09-PEXT-011) to O.R. and W.T., a grant from the European Research Council under the European Community's Seven Framework Programme FP7/20072013 (281422 TEEMBIO) to W.T., J.R., and F.B., and a grant from the German Research Foundation (DFG; SCHU 2259/5-1) to F.M.S. The calculations were run on the cluster of the Institut des Sciences de l'Evolution-Montpellier (ISEM). This is publication ISEM 2017-189.

\section{Literature Cited}

Auld, T. D., and A. J. Denham. 2006. How much seed remains in the soil after a fire? Plant Ecology 187:15-24.

Barker, N. P., A. Vanderpoorten, C. M. Morton, and J. P. Rourke. 2004. Phylogeny, biogeography, and the evolution of life-history traits in Leucadendron (Proteaceae). Molecular Phylogenetics and Evolution 33:845-860.

Beaulieu, J. M., D.-C. Jhwueng, C. Boettiger, and B. C. O'Meara. 2012. Modeling stabilizing selection: expanding the OrnsteinUhlenbeck model of adaptive evolution. Evolution 66:2369-2388.

Boettiger, C., G. Coop, and P. Ralph. 2012. Is your phylogeny informative? measuring the power of comparative methods. Evolution 66:2240-2251.

Bond, W. J., G. F. Midgley, and F. I. Woodward. 2003. What controls South African vegetation - climate or fire? South African Journal of Botany 69:79-91.

Bond, W. J., and J. J. Midgley. 2001. Ecology of sprouting in woody plants: the persistence niche. Trends in Ecology and Evolution $16: 45-51$.

Bond, W. J., and B. W. van Wilgen. 1996. Fire and plants. Chapman \& Hall, London.

Boucher, F. C., W. Thuiller, T. J. Davies, and S. Lavergne. 2014. Neutral biogeography and the evolution of climatic niches. American Naturalist 183:573-584.

Boucher, F. C., W. Thuiller, C. Roquet, R. Douzet, S. Aubert, N. Alvarez, and S. Lavergne. 2012. Reconstruction of high-alpine niches and cushion life form in the genus Androsace s.l. (Primulaceae). Evolution 66:1255-1268.

Brown, N. A. C. 1993. Promotion of germination of fynbos seeds by plant derived smoke. New Phytologist 123:575-584.

Burnham, K. P., and D. R. Anderson. 2002. Model selection and multimodel inference: a practical information-theoretic approach. Springer, New York

Butler, M. A., and A. A. King. 2004. Phylogenetic comparative analysis: a modeling approach for adaptive evolution. American Naturalist 164:683-695.
Cayuela, H., D. Arsovski, J. M. Thirion, E. Bonnaire, J. Pichenot, S. Boitaud, A. L. Brison, C. Miaud, P. Joly, and A. Besnard. 2016. Contrasting patterns of environmental fluctuation promote divergent life histories among populations of a long-lived amphibian. Ecology 97:980-991.

Charnov, E. L., and W. M. Schaffer. 1973. Life-history consequences of natural selection: Cole's results revisited. American Naturalist 107:791-793.

Childs, D. Z., C. J. E. Metcalf, and M. Rees. 2010. Evolutionary bethedging in the real world: empirical evidence and challenges revealed by plants. Proceedings of the Roval Societv B 277:3055-3064.

Clarke, P. J., D. M. Bell, and M. J. Lawes. 2015. Testing the shifting persistence niche concept: plant resprouting along gradient of disturbance. American Naturalist 185:747-755.

Cooper, N., and A. Purvis. 2010. Body size evolution in mammals: complexity in tempo and mode. American Naturalist 175:727-738.

Cooper, N., G. H. Thomas, C. Venditti, A. Meade, and R. P. Freckleton. 2016. A cautionary note on the use of Ornstein-Uhlenbeck models in macroevolutionary studies. Biological Journal of the Linnean Society 118:64-77.

Cowling, R. M., and B. B. Lamont. 1987. Post-fire recruitment of four co-occurring Banksia species. Iournal of Applied Ecology 24:645-658.

Cowling, R. M., and R. L. Pressey. 2001. Rapid plant diversification: planning for an evolutionary future. Proceedings of the National Academy of Sciences of the USA 98:5452-5457.

Cramer, M. D., and J. J. Midgley. 2009. Maintenance costs of serotiny do not explain weak serotiny. Austral Ecology 34:653-662.

Crawford, A. D., J. A. Plummer, R. J. Probert, and K. J. Steadman. 2010. The influence of cone age on the relative longevity of Banksia seeds. Annals of Botany 107:303-309.

de Klerk, H. M., A. M. Wilson, and K. Steenkamp. 2012. Evaluation of satellite-derived burned area products for the fynbos, a Mediterranean shrubland. International Journal of Wildland Fire 21:36-47.

de Villemereuil, P., J. A. Wells, R. D. Edwards, and S. P. Blomberg. 2012. Bayesian models for comparative analysis integrating phylogenetic uncertainty. BMC Evolutionary Biology 12:102. doi:10 .1186/1471-2148-12-102.

Enright, N., J. Fontaine, D. Bowman, R. Bradstock, and R. Williams. 2015. Interval squeeze: altered fire regimes and demographic responses interact to threaten woody species persistence as climate changes. Frontiers in Ecology and the Environment 13:265-272.

Enright, N., J. Fontaine, B. Lamont, B. Miller, and V. Westcott. 2014. Resistance and resilience to changing climate and fire regime depend on plant functional traits. Journal of Ecology 102:1572-1581.

Enright, N. J., and B. B. Lamont. 1992. Recruitment variability in the resprouting shrub Banksia attenuata and non-sprouting congeners in the northern sandplain heaths of southwestern Australia. Acta Oecologica 13:727-741.

Enright, N. J., R. Marsala, B. B. Lamont, and C. Wissel. 1998a. The ecological significance of canopy seed storage in fire-prone environments: a model for non-sprouting shrubs. Iournal of Ecology 86:946-949.

. 1998b. The ecological significance of canopy seed storage in fire-prone environments: a model for resprouting shrubs. Lournal of Ecology 86:960-973.

Evans, M. E. K., X. Aubriot, D. J. Hearn, M. Lanciaux, S. Lavergne, C. Cruaud, P. P. Lowry, II, and T. Haevermans. 2014. Insights on the evolution of plant succulence from a remarkable radiation in Madagascar (Euphorbia). Systematic Biology 63:698-711. 
Evans, M. E. K., D. J. Hearn, K. E. Theiss, K. Cranston, M. J. Donoghue, and K. E. Holsinger. 2011. Extreme environments select for reproductive assurance: evidence from evening primroses. New Phytologist 191:555-563.

Fischer, B., U. Dieckmann, and B. Taborsky. 2011. When to store energy in a stochastic environment. Evolution 65:1221-1232.

Gremer, J. R., and D. L. Venable. 2014. Bet hedging in desert winter annual plants: optimal germination strategies in a variable environment. Ecology Letters 17:380-387.

Hansen, T. F. 1997. Stabilizing selection and the comparative analysis of adaptation. Evolution 51:1341-1351.

He, T., J. G. Pausas, C. M. Belcher, D. W. Schwilk, and B. B. Lamont. 2012. Fire-adapted traits of Pinus arose in the fiery Cretaceous. New Phytologist 194:751-759.

Hernández-Serrano, A., M. Verdú, S. C. González-Martínez, and J. G. Pausas. 2013. Fire structures pine serotiny at different scales. American Journal of Botany 100:2349-2356.

Hijmans, R. J., S. E. Cameron, L. J. Parra, P. G. Jones, and A. Jarvis. 2005. Very high resolution interpolated climate surfaces for global land areas. International Journal of Climatology 25: 1965-1978.

Holmes, P. M. 2002. Depth distribution and composition of seedbanks in alien-invaded and uninvaded fynbos vegetation. Austral Ecology 27:110-120

Hutchinson, G. E. 1957. Concluding remarks. Cold Spring Harbor Symposia on Quantitative Biology 22:415-427.

Illing, N., C. Klak, C. Johnson, D. Brito, N. Negrao, F. Baine, V. van Kets, K. R. Ramchurn, C. Seoighe, and L. Roden. 2009. Duplication of the Asymmetric Leaves1/Rough Sheath 2/Phantastica $(A R P)$ gene precedes the explosive radiation of the Ruschioideae. Development Genes and Evolution 219:331-338.

Iwasa, Y. O. H., and T. Kubo. 1997. Optimal size of storage for recovery after unpredictable disturbances. Evolutionary Ecology 11:41-65.

Johnson, J. B., and K. S. Omland. 2004. Model selection in ecology and evolution. Trends in Ecology and Evolution 19:101-108.

Jump, A. S., J. M. Hunt, J. A. Martínez-Izquierdo, and J. Peñuelas. 2006. Natural selection and climate change: temperature-linked spatial and temporal trends in gene frequency in Fagus sylvatica. Molecular Ecology 15:3469-3480.

Keeley, J. E., W. J. Bond, R. A. Bradstock, J. G. Pausas, and P. W. Rundel. 2012. Fire in Mediterranean ecosystems: ecology, evolution and management. Cambridge University Press, Cambridge.

Koons, D. N., C. J. E. Metcalf, and S. Tuljapurkar. 2008. Evolution of delayed reproduction in uncertain environments: a life-history perspective. American Naturalist 172:797-805.

Kostikova, A., G. Litsios, N. Salamin, and P. B. Pearman. 2013 Linking life-history traits, ecology, and niche breadth evolution in North American eriogonoids (Polygonaceae). American Naturalist 182:760-774.

Kraaij, T., R. M. Cowling, and B. W. van Wilgen. 2013. Fire regimes in eastern coastal fynbos: imperatives and thresholds in managing for diversity. Koedoe 55:1104-1113.

Lamont, B. B., D. C. Le Maitre, R. M. Cowling, and N. J. Enright. 1991. Canopy seed storage in woody plants. Botanical Review 57:277-317.

Langan, S. J., F. W. Ewers, and S. D. Davis. 1997. Differential susceptibility to xylem embolism caused by freezing and water stress in two species of chaparral shrubs. Plant, Cell and Environment 20:425:437.
Linder, H. P., and A. G. Verboom. 2015. The evolution of regional species richness: the history of the southern African flora. Annual Review of Ecologv, Evolution, and Systematics 46:393-412.

Litsios, G., R. O. Wüest, A. Kostikova, F. Forest, C. Lexer, H. P. Linder, P. B. Pearman, N. E. Zimmermann, and N. Salamin. 2014. Effects of a fire response trait on diversification in replicated radiations. Evolution 68:453-465.

Lloret, F., H. Estevan, J. Vayreda, and J. Terradas. 2005. Fire regenerative syndromes of forest woody species across fire and climatic gradients. Oecologia 14:461-468.

Merow, C., A. M. Latimer, A. M. Wilson, S. M. McMahon, A. G. Rebelo, and J. A. Silander. 2014. On using integral projection models to generate demographically driven predictions of species' distributions: development and validation using sparse data. Ecography 37:1167-1183.

Mesquita, D. O., G. C. Costa, G. R. Colli, T. B. Costa, D. B. Shepard, L. J. Vitt, and E. R. Pianka. 2016. Life-history patterns in lizards of the world. American Naturalist 187:689:705.

Morris, W. F., C. A. Pfister, S. Tuljapurkar, C. V. Haridas, C. L. Boggs, M. S. Boyce, E. M. Bruna, et al. 2008. Longevity can buffer plant and animal populations against changing climatic variability. Ecology 89:19-25.

Münkemüller, T., F. C. Boucher, W. Thuiller, and S. Lavergne. 2015. Phylogenetic niche conservatism-common pitfalls and ways forward. Functional Ecology 29:627-639.

Ng, J., and S. D. Smith. 2014. How traits shape trees: new approaches for detecting character state-dependent lineage diversification. Journal of Evolutionary Biology 27:2035-2045.

Ogburn, M. R., and E. J. Edwards. 2015. Life history lability underlies rapid climate niche evolution in the angiosperm clade Montiaceae. Molecular Phvlogenetics and Evolution 92:181-192.

Ojeda, F., F. G. Brun, and J. J. Vergara. 2005. Fire, rain, and the selection of seeder and resprouter life-histories in fire-recruiting, woody plants. New Phytologist 168:155-165.

Olivieri, I., J. Tonnabel, O. Ronce, and A. Mignot. 2016. Why evolution matters for species conservation: perspectives from three case studies of plant metapopulations. Evolutionary Applications 9:196-211.

Onstein, R. E., G. J. Jordan, H. Sauquet, P. H. Weston, Y. Bouchenak-Khelladi, R. J. Carpentier, and H. P. Linder. 2016. Evolutionary radiations of Proteaceae are triggered by the interaction between traits and climates in open habitats. Global Ecology and Biogeography 25:1239-1251.

Orzack, S. H., and S. Tuljapurkar. 1989. Population dynamics in variable environments. VII. The demography and evolution of iteroparity. American Naturalist 133:901-923.

Pausas, J. G., and J. E. Keeley. 2014. Evolutionary ecology of resprouting and seeding in fire-prone ecosystems. New Phytologist 204:55-65.

Rajon, E., E. Desouhant, M. Chevalier, F. Débias, and F. Menu. 2014. The evolution of bet-hedging in response to local ecological conditions. American Naturalist 184:E1-E15.

R Development Core Team. 2012. R: a language and environment for statistical computing. R Foundation for Statistical Computing, Vienna, Austria. http://www.R-project.org.

Rebelo, A. G. 2001. A field guide to the proteas of southern Africa. Fernwood, Vlaeberg, South Africa.

Sanderson, M. J. 2002. Estimating absolute rates of molecular evolution and divergence times: a penalized likelihood approach. Molecular Phylogenetics and Evolution 19:101-109. 
Sauquet, H., P. H. Weston, N. P. Barker, C. L. Anderson, D. J. Cantrill, and V. Savolainen. 2009. Using fossils and molecular data to reveal the origins of the Cape proteas (subfamily Proteoideae). Molecular Phvlogenetics and Evolution 51:31-43.

Schaffer, W. M. 1974. Selection for optimal life histories: the effects of age structure. Ecology 55:291-303.

Schnitzler, J., T. G. Barraclough, J. S. Boatwright, P. Goldblatt, J. C. Manning, M. P. Powell, T. Rebelo, and V. Savolainen. 2011. Causes of plant diversification in the Cape biodiversity hotspot of South Africa. Systematic Biology 60:343-357.

Schulze, R. E. 1997. South African atlas of agrohydrology and climatology. Report TT82/96. Water Research Commission, Pretoria, South Africa.

Schurr, F. M., K. J. Esler, J. A. Slingsby, and N. Allsopp. 2012. Fynbos Proteaceae as model organisms for biodiversity research and conservation. South African Journal of Science 108:1446. doi:10.4102 /sajs.v108i11/12.1446.

Scott, M. F., and S. P. Otto. 2014. Why wait? three mechanisms selecting for environment-dependent developmental delays. Lournal of Evolutionary Biology 27:2219-2232.

Silvestro, D., A. Kostikova, G. Litsios, P. B. Pearman, and N. Salamin. 2015. Measurement errors should always be incorporated in phylogenetic comparative analysis. Methods in Ecology and Evolution 6:340-346.

Simons, A. M. 2011. Modes of response to environmental change and the elusive empirical evidence for bet hedging. Proceedings of the Roval Society B 278:1601-1609.

Smith, S. A., and J. Beaulieu. 2009. Life history influences rates of climatic niche evolution in flowering plants. Proceedings of the Roval Society B 276:4345-4352.

Starrfelt, J. and H. Kokko. 2012. Bet-hedging - a triple trade-off between means, variances and correlations. Biological Reviews 87: 742-755.

Tonnabel, J., A. Mignot, E. J. P. Douzery, A. G. Rebelo, F. M. Schurr, J. Midgley, N. Illing, F. Justy, D. Orcel, and I. Olivieri. 2014a. Convergent and correlated evolution of major life-history traits in the angiosperm genus Leucadendron (Proteaceae). Evolution 68:27752792.

- 2014b. Data from: Convergent and correlated evolution of major life-history traits in the angiosperm genus Leucadendron (Proteaceae). Evolution 68:2775-2792, Dryad Digital Repository, http://dx.doi.org/10.5061/dryad.18g80.1.

Tonnabel, J., I. Olivieri, A. Mignot, A. G. Rebelo, F. Justy, S. Santoni, S. Caroli, L. Sauné, O. Bouchez, and E. J. P. Douzery. 2014c. Developing nuclear DNA phylogenetic markers in the angiosperm genus Leucadendron (Proteaceae): a next-generation sequencing transcriptomic approach. Molecular Phylogenetics and Evolution 70:37-46.
Tonnabel, J., T. Van Dooren, J. Midgley, P. Haccou, A. Mignot, O. Ronce, and I. Olivieri. 2012. Optimal resource allocation in a serotinous non-sprouting plant species under different fire regimes. Lournal of Ecology 100:1464-1474.

Treurnicht, M., J. Pagel, K. J. Esler, A. Schutte-Vlok, H. Nottebrock, T. Kraaij, A. G. Rebelo, and F. M. Schurr. 2016. Environmental drivers of demographic variation across the global geographical range of 26 plant species. Journal of Ecology 104:331-342.

Tufto, J. 2015. Genetic evolution, plasticity, and bet-hedging as adaptive responses to temporally autocorrelated fluctuating selection: a quantitative genetic model. Evolution 69:2034-2049.

Tuljapurkar, S., J.-M. Gaillard, and T. Coulson. 2009. From stochastic demography to life histories and back. Philosophical Transactions of the Roval Society B 364:1499-1509.

van Wilgen, B. W. 2013. Fire management in species-rich Cape fynbos shrublands. Frontiers in Ecology and the Environment 11:e35-e44.

van Wilgen, B. W., G. G. Forsyth, H. de Klerk, S. Das, S. Khuluse, and P. Schmitz. 2010. Fire management in Mediterranean-climate shrublands: a case study from the Cape fynbos, South Africa. Journal of Applied Ecology 47:631-638.

Vilà-Cabrera, A., S. Saura-Mas, and F. Lloret. 2008. Effects of fire frequency on species composition in a Mediterranean shrubland. Ecoscience 15:519-528.

West, A. G., T. E. Dawson, E. C. February, G. F. Midgley, W. J. Bond, and T. L. Aston. 2012. Diverse functional responses to drought in a Mediterranean-type shrubland in South Africa. New Phytologist 195:396-407.

Williams, I. J. M. 1972. A revision of the genus Leucadendron (Proteaceae). Contributions from the Bolus Herbarium, no. 3. Bolus Herbarium, Cape Town.

Wilson, A. M. 2012. Fire and climate: the implications of global change in the Cape floristic region of South Africa. PhD diss. University of Connecticut, Storrs.

Wilson, A. M., A. M. Latimer, and J. A. Silander. 2015. Climatic controls on ecosystem resilience: postfire regeneration in the Cape floristic region of South Africa. Proceedings of the National Academv of Sciences of the USA 112:9058-9063.

Wilson, A. M., A. M. Latimer, J. A. Silander, A. E. Gelfand, and H. de Klerk. 2010. A hierarchical Bayesian model of wildfire in a Mediterranean biodiversity hotspot: implications of weather variability and global circulation. Ecological Modelling 221:106-112.

Zanne, A. E., D. C. Tank, W. K. Cornwell, J. M. Eastman, S. A Smith, R. G. FitzJohn, D. J. McGlinn, et al. 2014. Three keys to the radiation of angiosperms into freezing environments. Nature 506:89-92.

Associate Editor: Risa D. Sargent Editor: Judith L. Bronstein 